\title{
The Trend of Additives for Poly(vinyl chloride) as Photostabilizers: Review Article
}

\author{
Alaa Mohammed ${ }^{1}$, Alabbas Majeed ${ }^{1}$, Emad Yousif ${ }^{1} *$ and Rahimi M. Yusop ${ }^{2}$ \\ ${ }^{1}$ Department of Chemistry, College of Science, Al-Nahrain University, Baghdad-Iraq. \\ ${ }^{2}$ School of Chemical Science and Food Technology, Faculty of Science and Technology, \\ University Kebangsaan Malaysia, 43600 Bangi, Selangor, Malaysia \\ Corresponding author:*emad_yousif@hotmail.com
}

\begin{abstract}
Conservation of poly(vinyl chloride) from the ultraviolet light that causes degradation, have very attention in recent decades. PVC formularizations have a large number of additives playing fundamental functions during their conversion and adjusting the behavior properties of final products. In this review, various types of additives are briefly discussed to show their important properties and reasons for addition to their essential mechanisms that cause retardation of photodegradation. The additives including organotin(IV), UV screeners, organic UV absorber and freeradical scavengers. [DOI: 10.22401/ANJS.22.4.06]
\end{abstract}

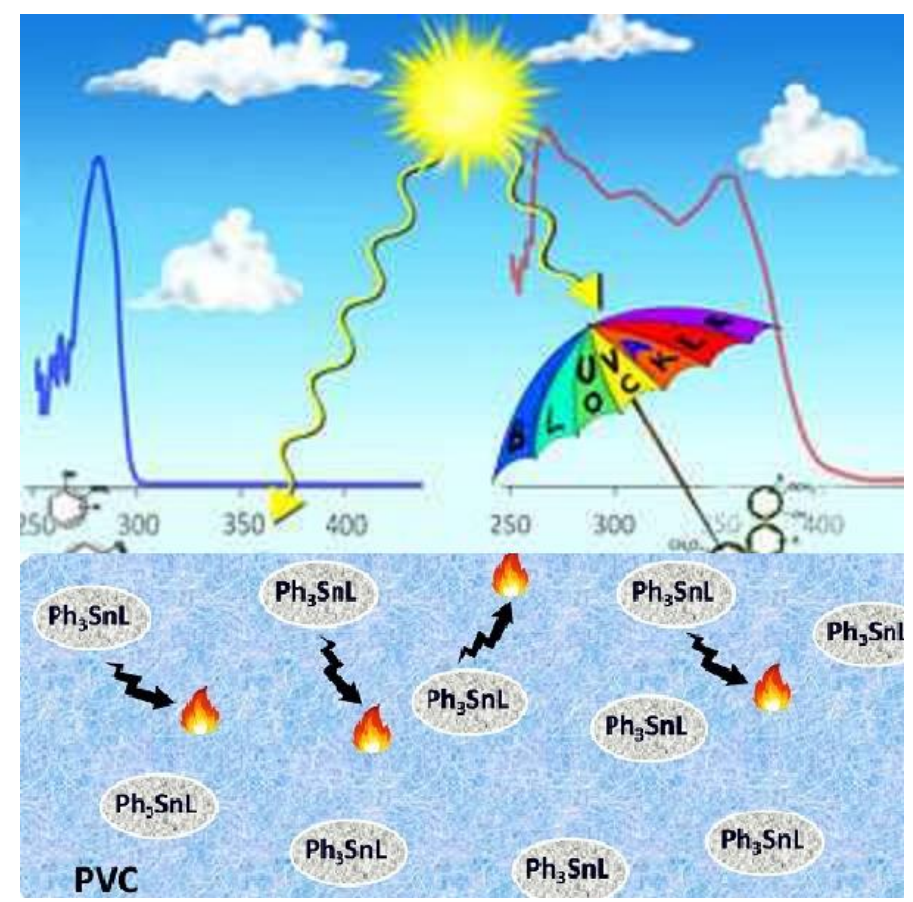

Keywords: PVC, Photo-stabilizers, organotin(IV), $\mathrm{TiO}_{2}$, organic UV absorber, HALS.

\section{Introduction}

Poly(vinyl chloride) is the generality commonly applied in the synthesis of plastic that came after polyethylene and polypropylene [1]. PVC has different important properties such as ascendant chemical resistance, mechanical properties, non-flammability, stability, and low cost [2]. PVC is one of the most important plastic materials used worldwide in various phases of the construction industry, such as pipes, fittings and gutters, window profiles and doors, ceiling tiles, various furniture and upholstery applications, coatings for electrical cables, etc., mainly because of its economy, in addition to its durability and ease of assembly [3]. However, PVC gradually degradation when exposed to the ultraviolet (UV) light that leads to reduces of mechanical performance. Can see the degradation of PVC in discoloration, loss of ductility and microcracking [4].

PVC undergoes degradation when exposure to UV-light neither in the absence of oxygen nor in presence. PVC consists of C-C, $\mathrm{C}-\mathrm{H}$, and $\mathrm{C}-\mathrm{Cl}$ bonds that expected does not absorb at wavelength of the light longer than 190-220 nm. The low poly(vinyl chloride) 
stability toward light due to the photoabsorbing structures, that inserted to the polymer through the polymerization manufacturing [5]. The main processes occurring in the photo- and photo-oxidative degradation of poly(vinyl chloride) polymers are [6]:

1. De-hydro-chlorination that proceeds and yields polyene structures with release HCI. This reaction may be controlled by decrease the surface region of the specimen and decrease the temperature. De-hydro-chlorination reduces with crosslinking processes. The participation of gaseous $\mathrm{HCl}$ speed up the photooxidation process of poly(vinyl chloride) in two ways [7]:

- $\mathrm{HCl}$ serves as a chain-transfer factor, which interacting with different radicals like POO-to give very interactive chlorine radicals.

- $\mathrm{HCl}$ dissolves metallic impurities and gives metallic salts that have a catalytic effect in oxidation reactions.

2. In the case of presence of oxygen, formation of carbonyl and hydro-peroxide group through crosslinking and chain scission reactions.

The photo-degradation of PVC takes place by the hydrogen abstraction process Fig.(1). Hydrogen abstraction carries out from the PVC backbone via the free radicals $\left(\mathrm{R}^{\circ}\right.$ or $\left.\mathrm{P}^{\circ}\right)$ that might be the formation of two kinds of polymer alkyl radicals [8]. In the oxygen presence, these radicals of polymer alkyl are extremely interactive toward oxygen molecules and form peroxy radicals ( $\left.\mathrm{PO}^{\circ}\right)$ of the polymer. The peroxy radicals of the polymer could extract hydrogen from other neighboring macromolecule and form polymer hydro-peroxides [9]. The photodecomposition of hydro-peroxy groups could be the formalization of ketone, aldehyde, acid and other groups [10], that can be controlled by FTIR spectroscopy technique. The hydroperoxide and ketone groups that formed may take part in the initiation step of photodegradation; however, they do not perform an important part in this reaction.

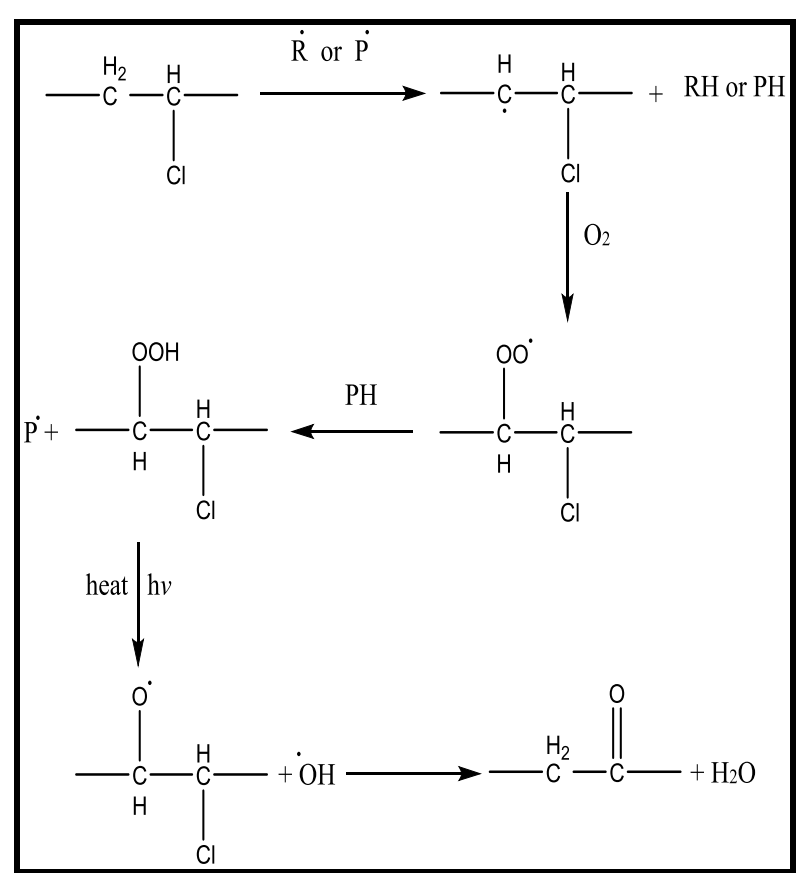

Fig.(1): Mechanism of poly(vinyl chloride) photo-degradation.

Therefore, different photo-stabilizer systems have been used to retardation the degradation of PVC.

\section{Organotin(IV) Complexes}

The main use of organotin (IV) compounds is to stabilize PVC against UV light [11]. Several di-organotin (IV) and tri-organotin complexes were syntheses by the reaction of $\mathrm{Ph}_{3} \mathrm{SnCl}, \mathrm{Ph}_{2} \mathrm{SnCl}_{2}, \mathrm{Bu}_{3} \mathrm{SnCl}, \mathrm{Me}_{3} \mathrm{SnCl}$ and $\mathrm{Me}_{2} \mathrm{SnCl}_{2}$ with different ligands such as benzamidoleucine [12], ciprofloxacin [13,14], benzamidoacetic acid [15], benzamidoglycin [16], furosemide [17], naproxen [32] and telmisartan [33]. 

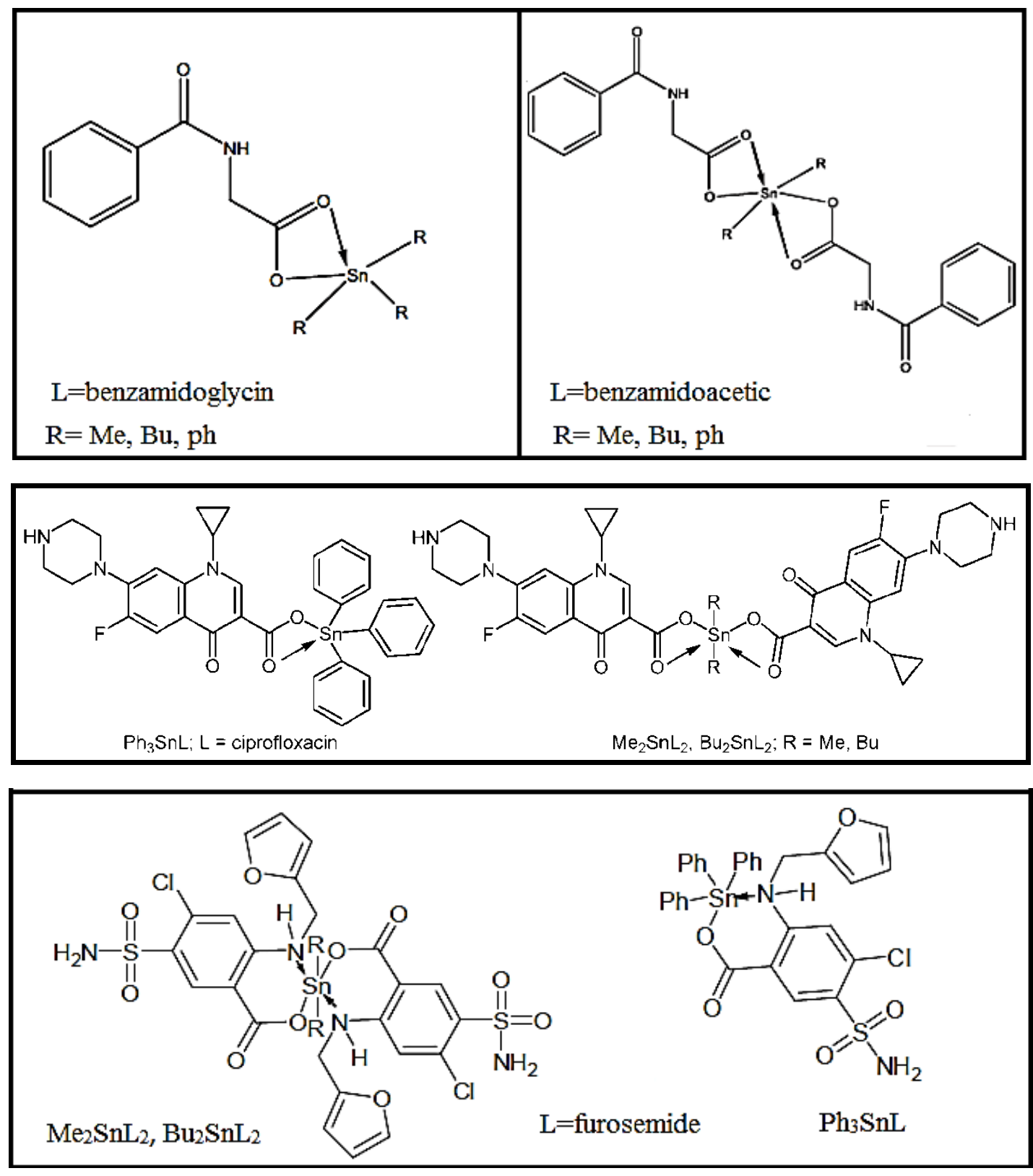

Fig.(2): Structures of organotin(IV) complexes with different ligands.

The PVC films containing a different concentration of several complexes $0.5 \%$ via weight were generated by the casting method by using tetrahydrofuran (THF) solvent. The photo-stabilization actions of these complexes were established by observing the polyene, carbonyl, and hydroxyl indices at a different time of irradiation of PVC films using FTIR Spectrophotometer (400-4000) $\mathrm{cm}^{-1}$ as display in Fig.(3). 


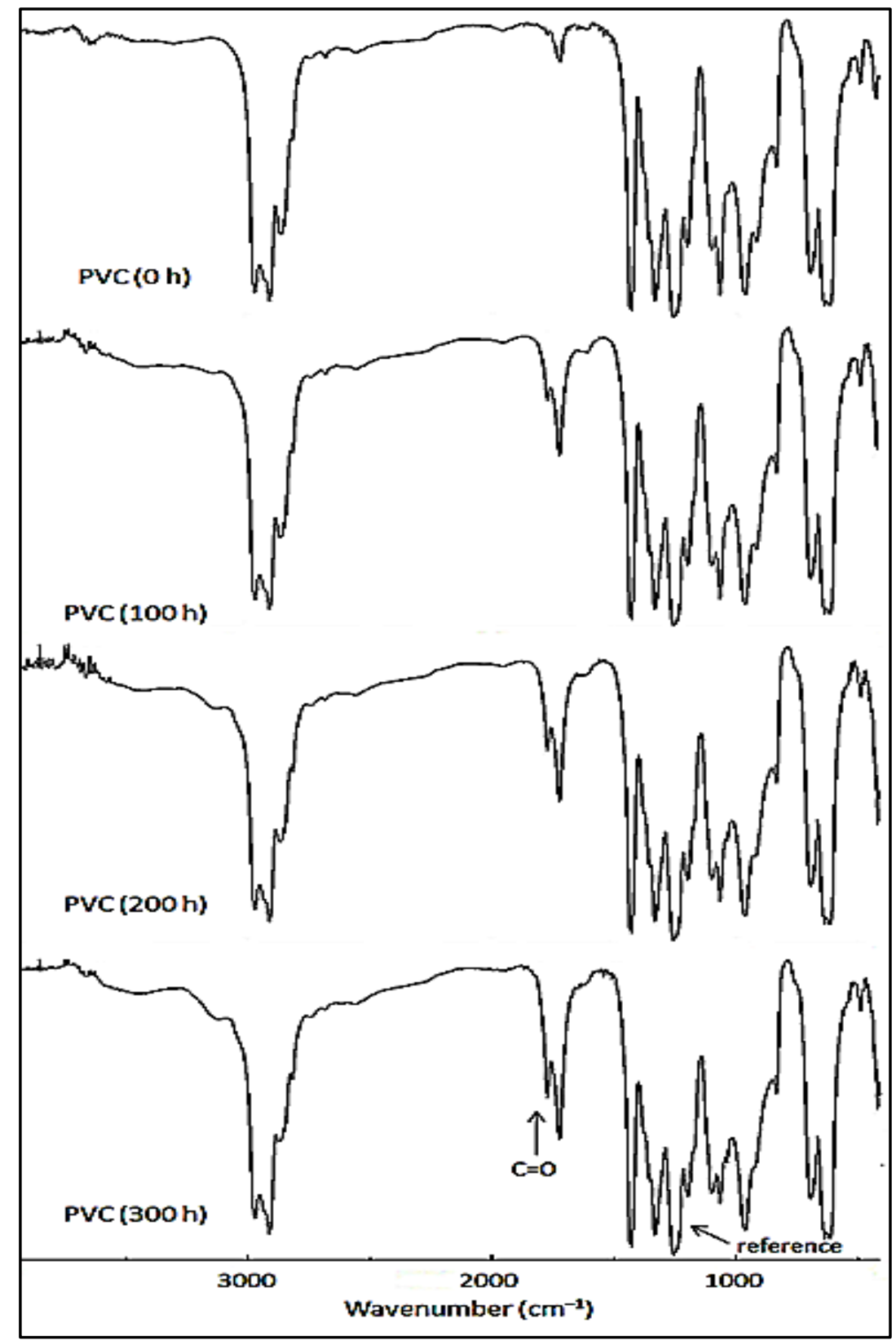

Fig.(3): Changes in FTIR spectra of PVC upon irradiation [18].

The bands of absorption for carbonyl, polyene, and hydroxyl groups represented at (1604, 1722 and 3500) $\mathrm{cm}^{-1}$, respectively. The growth rate of functional groups will be reduced when organotin complexes added to PVC paralleled to PVC without complexes.

The morphologies of PVC films surface that containing complexes were tested by using an atomic force microscope (AFM) and a scanning electron microscope (SEM). 


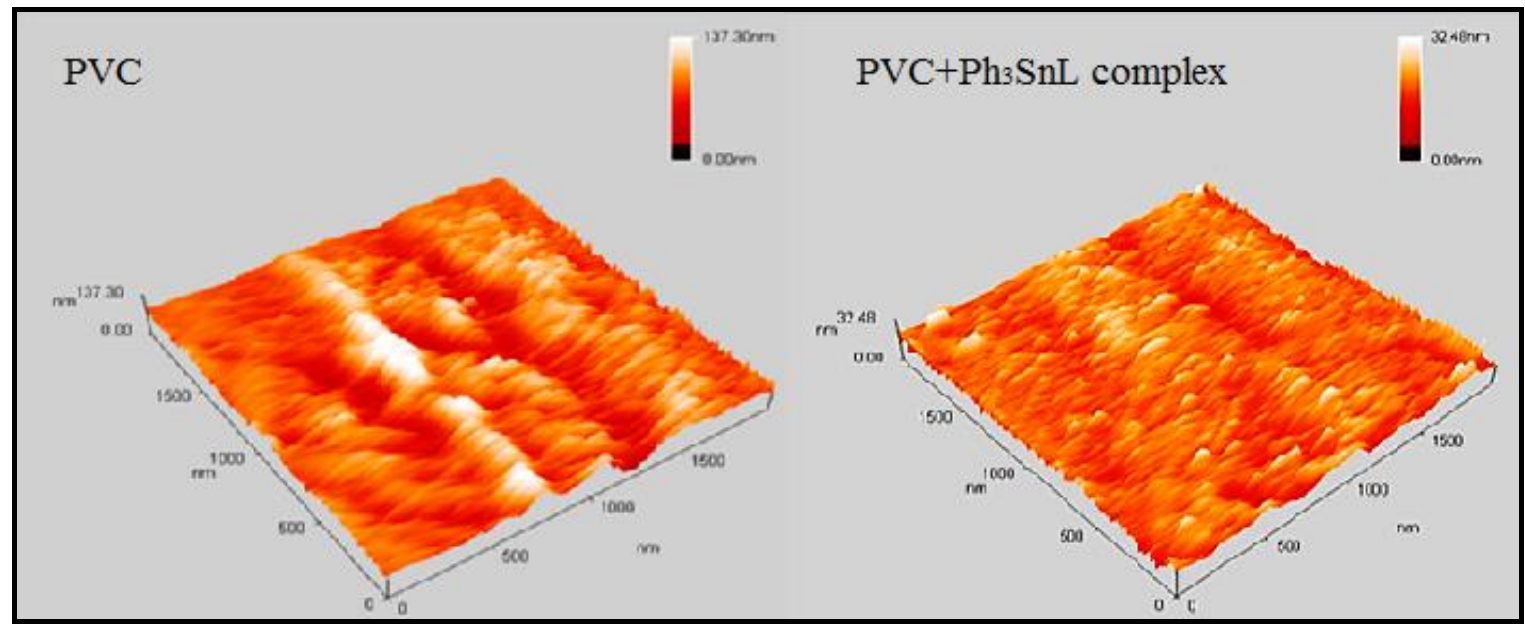

Fig.(4): Images of AFM for PVC film in the absence and presence of $P h_{3} S n L$ ( $L=$ furosemide) complex at 300h of irradiation [17].

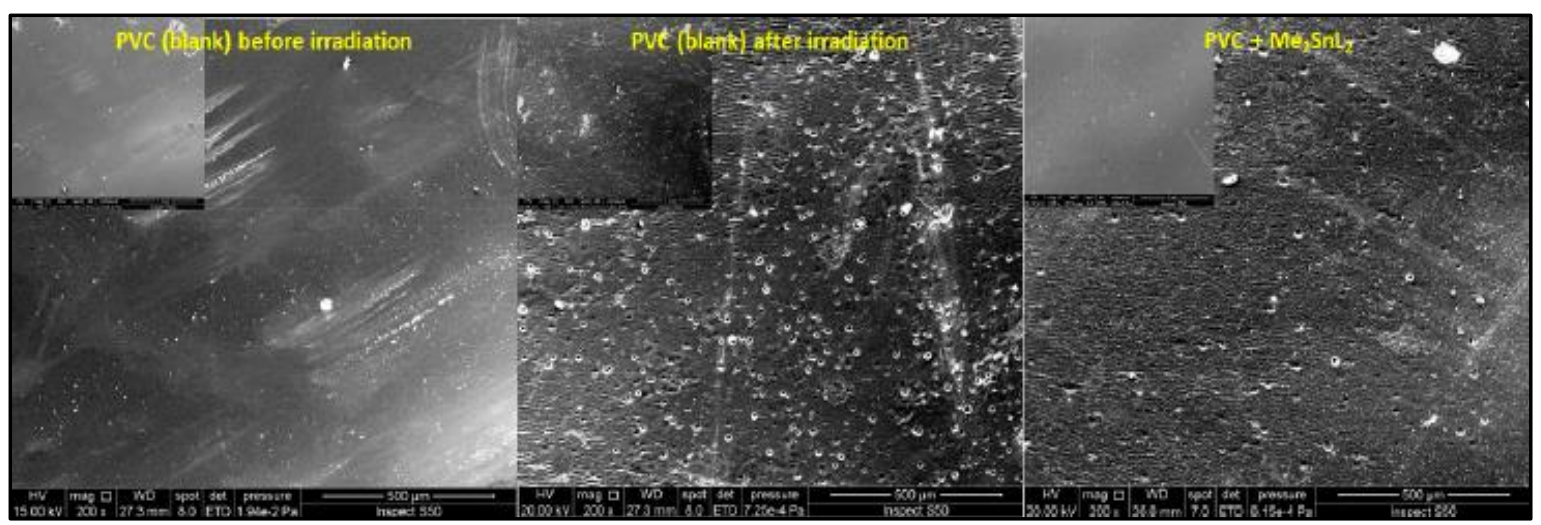

Fig.(5): SEM images of PVC films [13].

Fig.(4) shows the AFM images, the surface of PVC film containing organotin(IV) complex after irradiation was very smooth with low roughness factor $(\mathrm{Rq})$ compared with blank PVC film has a high roughness factor. Figure 5 shows the SEM images, the PVC film with organotin(IV) complex after irradiation exhibit fewer cracks compared with blank PVC film it was clear damage.

Various suggested mechanisms (figure 6) that elucidated the role of complexes for photo-stability of PVC films:

1. Complexes serve as $\mathrm{HCl}$ scavengers: Tin behaves as strong Lewis acid, therefore act as $\mathrm{HCl}$ scavenger, which is also known as a secondary stabilizer of PVC.

2. Complexes perform as peroxide decomposers: organotin(IV) complexes might be decomposing peroxides and inhibit photo-degradation of PVC.

3. Complexes act as radical scavengers: occurs by the complexation of additives and peroxide radicals and forms unreactive charge transfer complexes (especially containing conjugated $\pi$ system ligands).

4. Complexes act as UV Absorbers: when the ligands have conjugated or nonconjugated $\pi$-system, and heteroatoms, the organotin(IV) complexes will absorb UV light and dissipated this energy as heat (less harm).

$\mathrm{R}_{3} \mathrm{SnL}+\mathrm{UV} \longrightarrow \mathrm{R}_{3} \mathrm{SnL}^{*} \longrightarrow \mathrm{R}_{3} \mathrm{SnL}+$ heat 


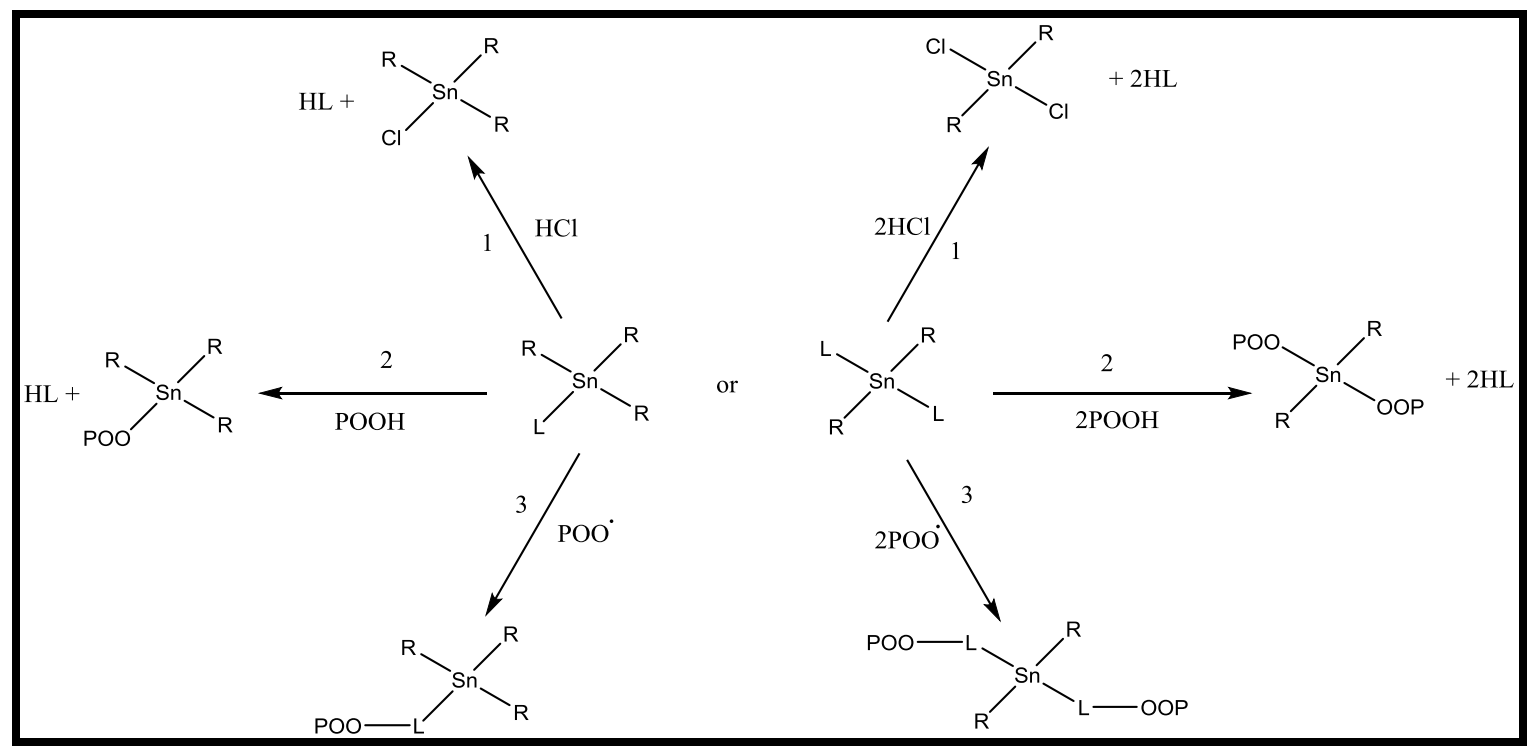

Fig. (6): Suggested mechanism of organotin(IV) complexes.

\section{UV Screeners}

Such as pigments including titanium dioxide using as UV screeners for different PVC. Titanium dioxide is an inorganic UV absorber and a very substantial pigment for PVC materials produced for outdoor uses. Regular concentrations of titanium dioxide that use for UV preservation in rang of (4-10) $w t \%$. The role of the titanium dioxide by absorbing or screen almost of the UV light and switch the energy of absorbed radiation into minimal hurtful thermal energy, that way departing little of energy absorbed by PVC [19].
The role of titanium dioxide is summarized in reflect of UV light and reduce the discoloration. The $\mathrm{TiO}_{2}$ must be used with different light stabilizers, however, $\mathrm{TiO}_{2}$ can delay the discolouration of irradiated PVC films efficiently, however, the surface undergoes oxidation and form the caverns Fig.(7) that bring by both the bad protection to surface of specimen and the photo-catalysis that is stimulated by UV light, water, and oxygen that accelerates deterioration [20].

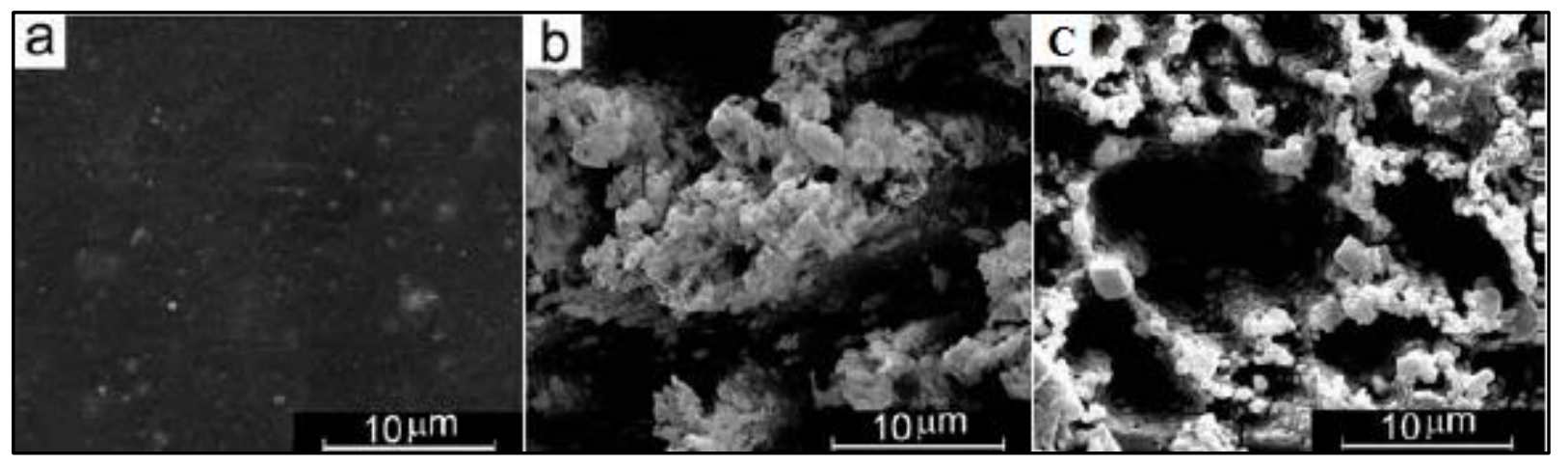

Fig.(7): SEM images of a-PVC blank before irradiation, b- PVC blank after 480 h irradiation, c$\mathrm{PVC}$ with $\mathrm{TiO}_{2}$ after $480 \mathrm{~h}$ irradiation.

In another study, investigated the influence of $\mathrm{TiO}_{2}$ on the changes of molecular and chemical that occur in PVC surface through accelerated weathering. The outcomes present that polyene and carbonyl groups were produced on the surface of the blank (PVC without $\mathrm{TiO}_{2}$ ) after 480 hours of accelerated weathering. However, in the presence of $\mathrm{TiO}_{2}$, the intensity of functional groups will decrease. Furthermore, a remarkable decrease in the number of average molecular weight $(\mathrm{Mn})$ and the consistency of an unsolvable clot 
was watched for blank after accelerated weathering, while the time desired for the $\mathrm{Mn}$ to come down increased in the participation of $\mathrm{TiO}_{2}$, and no unsolvable clot has appeared through weathering. These outcomes prove that two types of reactions (crosslinking and chain scission) occurred simultaneously in PVC without $\mathrm{TiO}_{2}$, whereas in the presence of $\mathrm{TiO}_{2}$, only the chain scission takes place. However, the presence of $\mathrm{TiO}_{2}$ has initiated the chain scission comparison to PVC in absence of $\mathrm{TiO}_{2}[21]$.

The role of $\mathrm{TiO}_{2}$ in $\mathrm{PVC}$ degradation [22]:

- Scatters visible light and to mask discoloration.

- Screens ultraviolet light and conserves the polymer by preventing immediate UVdegradation.

- $\mathrm{TiO}_{2}$ photo-catalytically converts the surface of PVC from harmful to smooth which leads to color faint.

\section{Organic UV Absorber}

The role of organic UV absorbers summarized by absorbing harmful UV radiation. These additives can absorb UV radiation more than the polymers (PVC) and exit. The excited states of these compounds will be relaxing to the ground state rapidly and efficiently re-emitted this radiation in longer wavelength (less harmful), which leads to high stabilization efficiency and excellent photostability [23].

It can be categorized as UV absorbers based on chemical class, such as benzophenones, benzotriazole, Schiff bases, etc. [24].

Mixtures of the 4-hydroxybenzophenone, 2,4-dihydroxybenzophenone and phenyl salicylate with their identical glucosides have been studied as photo-stabilizers for hard PVC. Benzophenones have a hydroxyl group and ether, that absorbs UV radiation efficiently, and would be absorbed and dissipate this harmful energy to the polymer as heat.

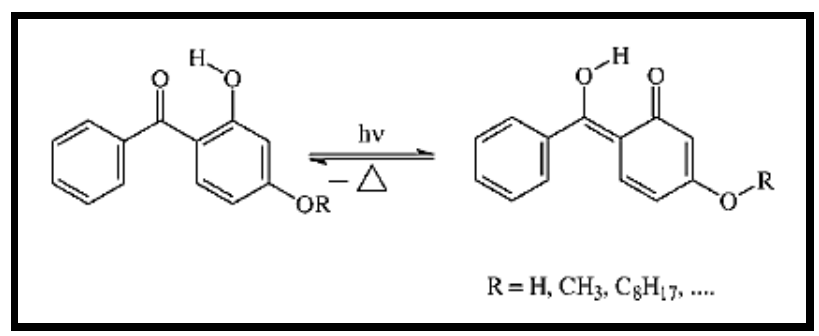

Fig.(8): Absorption of $U V$ light process by benzophenones.

The PVC films prepared by molding method having a concentration of $2 \%$ by weight of UV-absorbers or glucosides in the solvent of tetrahydrofuran. The mixtures exhibited photo-stabilizing effects by decreased rates of de-hydro-chlorination and decreased weight loss [25].

The $\left\{5,5^{\prime}\right.$-disulfide-bis[2-(2-hydroxy-3,5di-tert-butylphenyl)-2Hbenzotriazole]\} synthesized and applied as an efficient UV absorber (the maximum of absorption for DSBHTBB at $364 \mathrm{~nm}$ ) in order to prevent the photo-degradation of polymeric. The results revealed DSBHTBB be able to prevent the discolouration that results from treatment by irradiation of PVC [26].

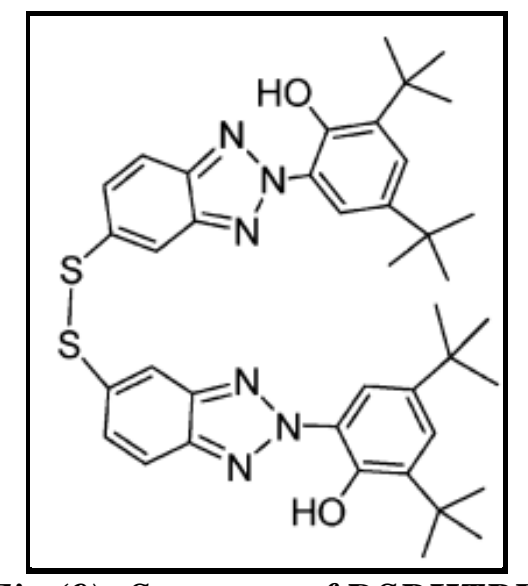

Fig.(9): Structure of DSBHTBB.

Schiff bases (2N-salicylidene-5(substituted)-1,3,4-thiadiazole) have been used as photo-stabilizer of polyvinyl chloride (PVC) films. The films of PVC having $0.5 \mathrm{wt}$ $\%$ of Schiff bases prepared by the molding method in tetrahydrofuran (THF) solvent. According to the experimental results, the stabilization may occur due to the absorption of UV light by the Schiff bases that lead to dissipate the energy as heat [27].

The suggested mechanism of the activity of Schiff bases involves direct absorption of 
UV light, the change in energy of photons that absorbed is due to the intramolecular proton transfer and then through an "internal conversion process to the ground state" where the energy dissipated as heat Fig.(10).

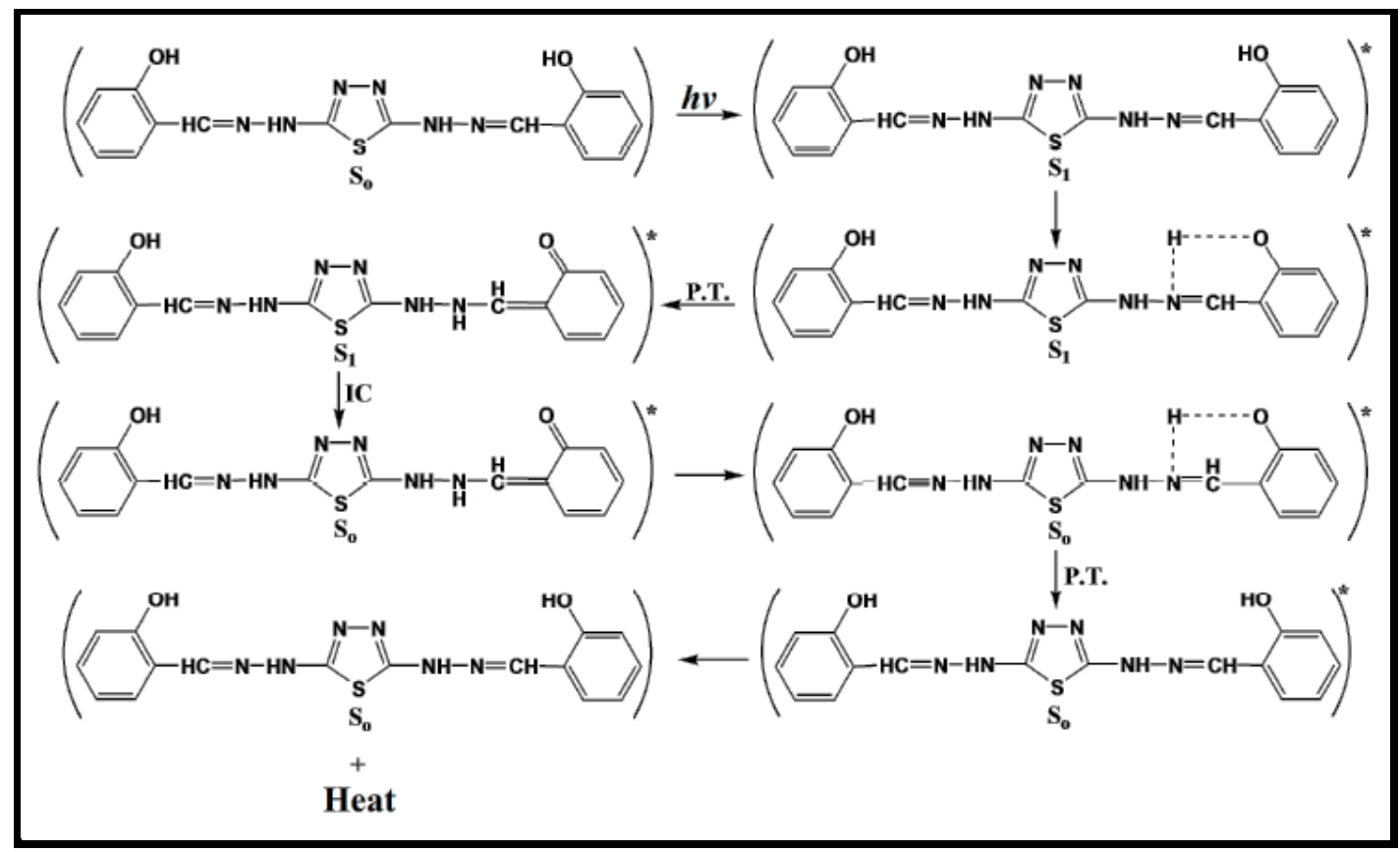

Fig. (10): The mechanism of the photo-stabilization of 2,5-di(arylhydrazones)-1,3,4-thiadiazole compounds as $U V$-absorber. Where "*” and "•" perform excited state and free radical, respectively [27].

\section{Free-radical Scavenger}

Hindered amine light stabilizers (HALS) produced in the 1970 s, act mostly as free radical scavengers, quenchers or peroxide decomposers, in another meaning, it dominates the market for light stabilizers. Hindered amines are originated from the tetra-methyl piperidine structure Fig. (11) [28].

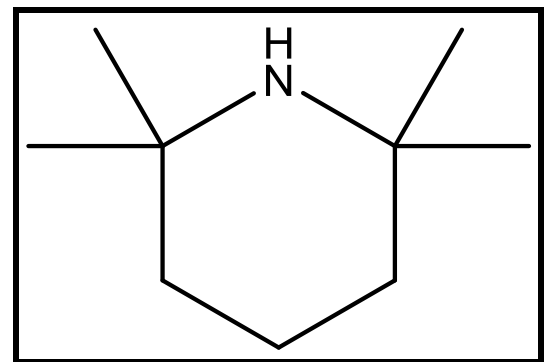

Fig. (11): 2,2,6,6-tetramethylpiperidine.

HALS has a large difference in structures that variation in molecular weights, with minimal evaporation and perfect stabilization at rising temperatures. They can be used in the presence or absence of UV absorbers and quenchers, which provide surface preservation.
It is at low concentrations $(0.1 \%)$, with high efficiency [29].

Two types of piperidine derivatives with low-molecular-weight and a high molecular weight hindered amine light stabilizers (HALS) that used with and without ultraviolet absorbers [(2-(2-hydroxy-3-tert-butyl-5methylphenyl)-5-chlorobenzotriazole) and (2hydroxy-4-(octyloxy) benzophenone)] inset to plasticized PVC specimens. PVC samples with HALS and UVA revealed excellent results (differences of color, mechanical properties, and FTIR) and show avoid discolouring and photo-oxidation due to irradiation [30].

The accurate mechanism of stabilization for hindered amines efficiency suggested that they scavenge free radicals by a mechanism demonstration in Fig.(12). Initially, oxidation of hindered amine and forming nitroxyl radical that interacts with free radicals to compose an alkoxyamine, which interacts with a peroxy radical to reproduce the main hindered amine, that starts the circle again [31]. 


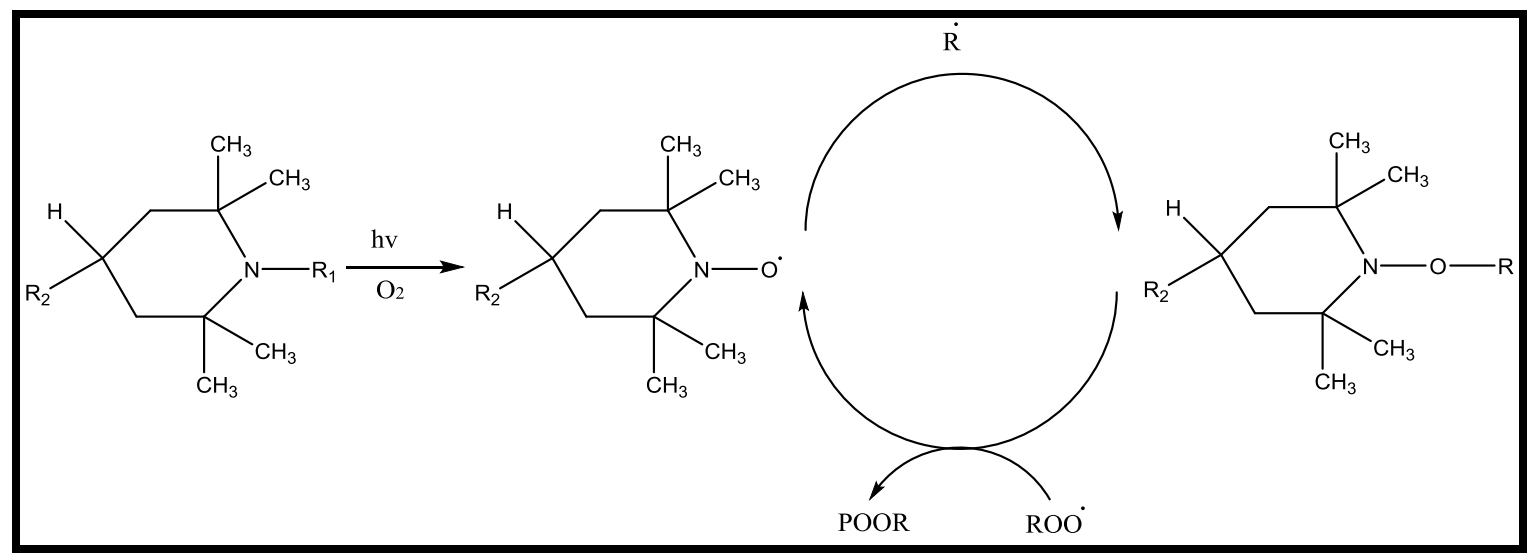

Fig.(12): Stabilization mechanism of HALS.

\section{Conclusion}

Due to the photo-degradation that occurs for PVC when exposing to the UV light, we need to use additives to retardation of this degradation, while maintaining the properties of PVC. Such additives are organotin (IV) complexes, $\mathrm{TiO}_{2}$ pigments, benzophenones, benzotriazole, Schiff bases and hindered amine light stabilizers. By comparing among the researches that discuss in this review, HALS and $\mathrm{TiO}_{2}$ could be used with other UV absorbers as photo-stabilizer systems for PVC, while organotin(IV) complexes and organic UV absorber more efficient and can be used without other photo-stabilizer systems.

\section{Acknowledgments}

This work was supported by Al-Nahrain University.

\section{References}

[1] Wypych G., PVC Formulary, CP, 1, 2015.

[2] Kumar A., Gupta R., Fundamentals of Polymer Engineering, Marcel Dekker, 5052, 2003.

[3] Akovali G., Plastic materials: polyvinyl chloride (PVC), Toxicity of Building Materials, 23-53, 2012.

[4] Ho B., Development of light-stable PVC stabilizer systems for rigid weather able applications, J. Vinyl Technol, 162-166, 1984.

[5] Rabek J., Polymer Photodegradation, Springer Science, 152, 1995.

[6] Titow W., PVC Plastics Properties, Processing, and Applications, Elsevier, 103, 1990.
[7] Yousif E., Hasan A., Photostabilization of poly(vinyl chloride) - Still on the run, Journal of Taibah University for Science, 9, 421-448, 2015.

[8] Owen E., Degradation and Stabilisation of PVC, Elsevier, 106, 1984.

[9] Wypych G., PVC Degradation \& Stabilization, CP, 206-207, 2015.

[10] Hussain Z., Alsayed R., Alwash A., Ahmed A., Noaman R., Jawad A.H., Yousif E. Controlling the PhotoDegradation Rate Constant of PS Containing Nickel(II) Complex. AlNahrain J. of Sci. 22, 8-17, 2019.

[11] Astruc D., Organometallic Chemistry and Catalysis, Springer, 336-338, 2007.

[12] Yousif E., Salimon J., Salih N., Jawad A., Win Y., New stabilizers for PVC based on some diorganotin(IV) complexes with benzamidoleucine, Arabian Journal of Chemistry, 9, S1394-S1401, 2016.

[13] Ghazi D., El-Hiti G., Yousif E., Ahmed D., Alotaibi M., The effect of ultraviolet irradiation on the physicochemical properties of poly(vinyl chloride) films containing organotin(IV) complexes as photostabilizers, Molecules, 23(2), 1-15, 2018.

[14] Ghazi, D., Yousif , E., S Ahmed, D., Thamer, H., Noaman, R., Jassim Hussien, N., M Yusop, R., \& H Jawad, A. (2019). Photo-Physical Studies of PVC Mixed with Organotin (IV) Complexes. AlNahrain Journal of Science, 22(3), 1-7, 2019.

[15] Yousif E., Salimon J., Salih N., New photostabilizers for PVC based on some diorganotin(IV) complexes, Journal of 
Saudi Chemical Society, 19(2), 133-141, 2015.

[16] Yousif E., Triorganotin(IV) complexes photo-stabilizers for rigid PVC against Photodegradation, Journal of Taibah University for Science, 7, 79-87, 2013.

[17] Ali M., El-Hiti G., Yousif E., Photostabilizing Efficiency of Poly(vinyl chloride) in the Presence of Organotin(IV) Complexes as Photostabilizers, molecules, 21(1151), 1-16, 2016.

[18] El-Hiti G., Hayal M., Ahmed A., Hamad B., Ahmed D.S., Ahmed A., Hashim H., Yousif E., The Morphology and Performance of Poly(Vinyl Chloride) Containing Melamine Schiff Bases against Ultraviolet Light, Molecules, 24, 803, (115), 2019.

[19] Birmingham J., The Effect of Surface Oxidation and Titanium Dioxide on Exterior PVC Color Retention, Journal Of Vinyl \&Additive Technology, 1(2), 84-87, 1995.

[20] Zhang X., Pi H., Guo S., Photostabilizing Efficiency of Ultraviolet Light Stabilizers for Rigid Poly(vinyl chloride) Against Photo-Oxidation, Polymer Engineering and Science, 1-11, 2012.

[21] Yang T., Noguchi T., Isshiki M., Wu J., Effect of titanium dioxide on chemical and molecular changes in PVC sidings during QUV accelerated weathering, Polymer Degradation and Stability, 104, 33-39, 2014.

[22] Gao A., Bolt J., Feng A., Role of titanium dioxide pigments in outdoor weathering of rigid PVC, Plastics, Rubber and Composites, 37(9/10), 397-402, 2008.

[23] McKeen L., The Effect of UV Light and Weather on Plastics and Elastomers, Elsevier, 17, 2013.

[24] Otterstedt J., Photostability and molecular structure, The Journal of Chemical Physics 58(12), 5716-5725, 1973.

[25] Rabie S., Nada A., Glucoside/(UV Absorber) Mixtures as Photostabilizers for Rigid PVC, Journal Of Vinyl \& Additive Technology, 79-83, 2008.

[26] Xu S., Cao D., Chen M., Synthesis and Characterization of a Bisbenzotriazole Derivative and Its Application in PVC as an Ultraviolet Absorber, Journal Of Vinyl \& Additive Technology, 195-200, 2007.

[27] Yousif E., Al-Amiery A, Kadihum A., Kadhum A., Mohamad A., Photostabilizing Efficiency of PVC in the Presence of Schiff Bases as Photostabilizers, Molecules, 20, 1988619899, 2015.

[28] Maier C., Calafut T., 3-Additives, Plastics Design Library, 27-47, 1998.

[29] Drobny J., Handbook of Thermoplastic Elastomers, Elsevier, 18, 2014.

[30] Chai R., Chen S., Zhang J., Synergistic Effect of Hindered Amine Light Stabilizers/Ultraviolet Absorbers on the Plasticized PVC during Photo-Irradiation, Journal of Applied Polymer Science, 1-9, 2012.

[31] Cristofoli K., Brandalise R., Zeni M., Photostabilized LDPE Films with UV Absorber and HALS as Protection against the Light for Rosé Sparkling Wine, J Food Process Technol, , 3(7), 1-7, 2012.

[32] Hadi A.G., Yousif E., El-Hiti G.A., Ahmed D.S., Jawad K., Alotaibi M.H., Hashim H., Long-Term Effect of Ultraviolet Irradiation on Poly(vinyl chloride) Films Containing Naproxen Diorganotin(IV) Complexes, Molecules 24, 2396, 2019.

[33] Hadi A.G., Jawad K., El-Hiti G.A., Alotaibi M.H., Ahmed A.A., Ahmed D.S., Yousif E. Photostabilization of Poly(vinyl chloride) by Organotin(IV) Compounds against Photodegradation. Molecules, 24, 3557, 2019. 